\title{
Profile and complication rate of thyroid surgeries performed in a tertiary care teaching hospital, a prospective observational study
}

\author{
Vijaiaboobbathi $\mathbf{S}^{1}$, Karpagavel $C^{2}$. \\ ${ }^{1}$ Dr. Vijaiaboobbathi Sathiah, Assistant Professor, ${ }^{2}$ Dr. Karpagavel Chandrabose, Associate professor; both authors are \\ attached with Department General Surgery, Velammal Medical College Hospital, Madurai, Tamil Nadu.
}

Corresponding Author: Dr. Karpagavel Chandrabose, 280, Srisakthi Vinayagarillam, Periyar Road, Usilam Patty, Madurai, Tamil Nadu, India. E-mail: drkarpagavel@gmail.com

\begin{abstract}
Background: One of the most common endocrine disorder is the thyroid diseases. The prevalence and pattern of these conditions depends on sex, age, ethnic and geographic patterns. The incidence of thyroid nodules increases with the age hence benign and malignant thyroid disease is common in the elderly population. Aim: To compare the complication rate of various thyroid surgeries for benign and malignant diseases in a tertiary care teaching hospital. Methods: This study was a prospective observational study, Velammal medical college hospital at Tamil Nadu from December 2018-June 2019. The patients who underwent thyroid surgery for various thyroid disorders were enrolled in the study. Results: Out of1 17 cases, 107 were women and 10 were men. Multinodular goiter (MNG)was the most common (38.46\%) condition, followed by solitary nodule (29.06\%) and toxic MNG (18.8\%). Among women, 40.19\% were identified with multinodular goiter followed by solitary nodule (28.97\%). Subtotal thyroidectomy was performed for $88.89 \%$ of MNGs, while $91.18 \%$ of the solitary nodule were managed by hemithyroidectomy Majority of the patients with toxic MNG underwent subtotal thyroidectomy with $99.91 \%$. While $84.61 \%$ of the patients with thyroid cancer were treated by total thyroidectomy. The overall incidence of complications was $27.35 \%$. The incidence rate of complications was high in patients with malignant disease, as compared to benign disease $(69.23 \%$ in Malignant Vs $36.36 \%$ in toxic MNG and 24.44\% in MNG). Conclusion: Through the present study, it was concluded that the complications associated with the different thyroid surgeries and various precautions that can be taken to reduce the complications.
\end{abstract}

Keywords: Thyroid, Thyroidectomy, Complications, Multinodular goiter, Surgery

\section{Introduction}

Worldwide, diseases associated with thyroid gland is one of the most common endocrine disorder. Various benign and malignant thyroid conditions are amenable to treatment by surgical intervention. These surgical procedures may range from hemithyroidectomy to subtotal, near-total and total thyroidotomies. The choice of surgical procedure may depend on the type and extent of the disease [1,2].

The surgical procedures on thyroid may be associated with a plethora of transient or permanent complications [3]. The most common immediate surgical complication of total thyroidectomy is post-operative hypocalcemia [4]. The permanent recurrent laryngeal nerve palsy and permanent hypoparathyroidism are the major complications followed by total thyroidectomy [5]. The

Manuscript Received: $20^{\text {th }}$ July 2019

Reviewed: $30^{\text {th }}$ July 2019

Author Corrected: $4^{\text {th }}$ August 2019

Accepted for Publication: $8^{\text {th }}$ August 2019 pressure complaints, shorter complaining period, malignancy and more radical surgeries are the factors influencing thyroidectomy complications [3]. The risk of permanent complications is high in patients who performed surgery for the recurrence of benign thyroid disease [6]. Total thyroidectomy is considered as the treatment of choice for various thyroid diseases except in case of thyroid carcinoma and a few benign diseases due to its risk involved [1]. It is performed mainly in malignant thyroid disease as it can reduce the rate of recurrence and reoperations. The risk of recurrence is high with subtotal thyroidectomy performed for benign thyroid diseases [6].

The reported rate of complications after surgery for benign thyroid disease ranges from 0 to $1.8 \%$. The risk of permanent complications reported is 3 to $4 \%$. The complication rate of thyroid surgery for malignant thyroid is high as compared to benign thyroid disease. 


\section{Original Research Article}

The reported incidence of permanent recurrent laryngeal nerve injury is 0 to $4 \%$ [7]. The patient condition, thyroid disease, surgeon's experience and type of surgery are the factors associated with the postoperative results from thyroid surgery [3]. The hyperthyroidism and goiter size are the independent factors for the development of complication in total thyroidectomy [8].

Complications associated with total thyroidectomy can be reduced by performing surgeon's experience, monitoring and identifying patients at risk [9].

A thorough understanding of the profile of thyroid surgeries and the likely complications is essential for surgeons dealing with them. This understanding can help them in minimizing the incidence of complications and effective risk communication to the patients. But the studies on the subject are scarce on the Indian population.

Hence, the present study was performed to compare the complication rates after thyroidectomy for benign disease and malignant disease and also to identify the ways to reduce the complication rates.

\section{Aims and Objectives}

1. The study aims to compare complication rates of subtotal thyroidectomy, near-total thyroidectomy, hemithyroidectomy and total thyroidectomy in a cohort of patients undergoing surgery for various thyroid disorders.

2. To compare complication rates after thyroidectomy for benign disease and malignant disease.

\section{Materials and Methods}

Study setting: The study was conducted on patients who underwent thyroid surgery, for various thyroid disorders at the Velammal medical college hospital, Madurai, Tamil Nadu, India.

Study design: The current study was a prospective observational study.

Study period: The study was conducted between December 2018 to June 2019.

Sample size: This study has 117 included undergoing thyroid surgery.

Inclusion criteria: The study had included, all the adult patients, of both genders, undergoing surgery for various conditions, including non-toxic multinodular goiter (MNG), toxic multinodular goiter, nontoxic solitary nodular goiter, colloid goiter and thyroid carcinoma.

Exclusion criteria: The study had excluded pediatric patients

Data collection procedure: Data was collected be retrospective case record review, using a structured proforma

Data analysis: Data was analyzed using IBM SPSS statistical software version 23. Descriptive analysis was done using mean and standard deviation for quantitative variables, frequency and proportion of categorical variables.

Ethical consideration \& permission: Considering the retrospective nature of the study, the study was not subjected to approval of Institutional Human ethical committee and was also not possible to obtain informed written consent from the participants.

Confidentiality of the study participants was maintained throughout the reporting of study results.

Any scoring system: No scoring systems were used.

Surgical procedure: Operations were performed by different levels of faculty. When the procedures were performed by postgraduates, they were done under the close supervision of senior surgeons. For all the included patients a through history was elicited, followed by a complete physical examination.

The basic biochemical and hematological investigations were done for all patients. It was decided to request special investigation like thyroid hormone profile and serum calcium estimation only in selected cases, where a disturbance in the functional status was suspected.

Vocal cords were examined pre-operatively by indirect laryngoscope in all the patients, whereas postoperative vocal cord examination was performed only when hoarseness occurred. Patients were classified as having hypocalcemia (hyperparathyroidism) if both clinical and biochemical (a fall in corrected serum calcium supplementation supportive evidence were present.

FNAC was done for all patients based on the final diagnosis the treatment was given as advised by the experts. The details of each patient were documented as shown in a structured proforma. 


\section{Original Research Article}

\section{Results}

Table-1: Gender wise frequency of different types of thyroid surgeries performed.

\begin{tabular}{|c|c|c|c|}
\hline & Male $(\mathbf{N}=\mathbf{1 0})$ & Female (N=107) & Total (N=117) \\
\hline Colloid goiter & $1(10 \%)$ & $2(1.87 \%)$ & $3(2.56 \%)$ \\
\hline Solitary nodule & $3(30 \%)$ & $31(28.97 \%)$ & $34(29.06 \%)$ \\
\hline Multinodular goiter & $2(20 \%)$ & $43(40.19 \%)$ & $45(38.46 \%)$ \\
\hline Toxic MNG & $3(30 \%)$ & $19(17.76 \%)$ & $22(18.8 \%)$ \\
\hline Thyroid cancer & $1(10 \%)$ & $12(11.21)$ & $13(11.1 \%)$ \\
\hline
\end{tabular}

Out of 117 cases, $38.46 \%$ of patients underwent thyroid surgery for multinodular goiter followed by the solitary nodule, toxic MNG, thyroid cancer and colloid goiter with $29.06 \%, 18.8 \%, 11.1 \%$ and $2.56 \%$ respectively. Among females, $40.19 \%$ of the patients were identified with multinodular goiter followed by solitary nodule, toxic MNG, thyroid cancer and colloid goiter with $28.97 \%, 17.76 \%, 11.21 \%$ and $1.87 \%$ respectively whereas among males majority was identified with solitary nodule and toxic MNG with $30 \%$ each followed by multinodular goiter, colloid goiter and thyroid cancer with $20 \%, 10 \%$ and $10 \%$ (Table 1 ).

Table-2: Condition wise surgical procedure performed in the study population.

\begin{tabular}{|l|c|c|c|c|c|}
\hline \multirow{2}{*}{ Disease } & \multirow{2}{*}{$\begin{array}{c}\text { Total no } \\
\text { of } \\
\text { patients }\end{array}$} & $\begin{array}{c}\text { Hemithyroidectomy } \\
\text { (no of PTS \& \%) }\end{array}$ & $\begin{array}{c}\text { Subtotal } \\
\text { thyroidectomy }\end{array}$ & $\begin{array}{c}\text { Near total } \\
\text { Thyroidectomy }\end{array}$ & $\begin{array}{c}\text { Total } \\
\text { Thyroidectomy }\end{array}$ \\
\cline { 3 - 6 } & 3 & - & - & - & $3(00 \%)$ \\
\hline Colloidgoiter & 34 & $31(91.18 \%)$ & $3(8.82 \%)$ & & - \\
\hline Mulitarynodule & 45 & $2(4.44 \%)$ & $40(88.89)$ & $1(2.22)$ & $2(4.44)$ \\
\hline Toxic MNG & 22 & - & $20(90.91)$ & - & $2(9.09)$ \\
\hline Thyroid cancer & 13 & $1(7.69 \%)$ & - & $1(7.69 \%)$ & $11(84.61 \%)$ \\
\hline Total (117) & $\mathbf{1 1 7}$ & $\mathbf{3 4}(\mathbf{2 9 . 0 6 \% )}$ & $\mathbf{6 3 ( 5 3 . 8 5 \% )}$ & $\mathbf{2 ( 1 . 7 1 \% )}$ & $\mathbf{1 7}(\mathbf{1 4 . 5 3 \% )}$ \\
\hline
\end{tabular}

Majority of the patients with multinodular goiter underwent subtotal thyroidectomy with $88.89 \%$ followed by hemithyroidectomy with $4.44 \%$. $91.18 \%$ of patients performed hemi thyroidectomy surgery for a solitary nodule, followed by subtotal thyroidectomy with $8.82 \%$. Out of 22 patients, $90.91 \%$ of patients performed subtotal thyroidectomy surgery for toxic MNG followed by total thyroidectomy with $9.09 \%$. Majority of the patients with thyroid cancer performed total thyroidectomy with $84.61 \%$ followed by near-total thyroidectomy and hemithyroidectomy with $7.69 \%$ and $7.69 \%$ respectively. Total thyroidectomy was the only surgery performed in patients with colloid goiter (Table2).

Table-3: Incidence of complications in the study population.

\begin{tabular}{|l|c|c|c|}
\hline Parameter & Total Number & $\begin{array}{c}\text { Total number of people } \\
\text { with complications }\end{array}$ & $\begin{array}{c}\text { Percentage of } \\
\text { complications }\end{array}$ \\
\hline Overall complications & 117 & 32 & $27.35 \%$ \\
\hline Thyroid disorder wise & 3 & 3 & $100 \%$ \\
\hline Colloid and recurrent goiter & 34 & 1 & $2.94 \%$ \\
\hline Solitary nodule of thyroid & 45 & 11 & $24.44 \%$ \\
\hline Multinodular goiter & 22 & 8 & $36.36 \%$ \\
\hline Toxic multinodular goiter & 13 & 9 & $69.23 \%$ \\
\hline Thyroid carcinoma & \multicolumn{2}{|c|}{} \\
\hline Type of surgery wise & 34 & 1 & $2.94 \%$ \\
\hline Hemithyroidectomy & 63 & 15 & $23.80 \%$ \\
\hline Subtotal thyroidectomy & 2 & 1 & $50 \%$ \\
\hline Near total thyroidectomy & 17 & 15 & $88.23 \%$ \\
\hline Total thyroidectomy & \multicolumn{2}{|c|}{} \\
\hline Benign Vs Malignant & 104 & 23 & $22.12 \%$ \\
\hline Benign disorders & 13 & 9 & $69.23 \%$ \\
\hline Malignant diseases &
\end{tabular}




\section{Original Research Article}

The overall incidence of complications was $27.35 \%$ in the study population. Among the disease conditions, all the 3 subjects with Colloid and recurrent goiter developed complications. Among the people thyroid carcinoma, $69.23 \%$ developed complications. The proportion of people with complications was $36.36 \%$ and $24.44 \%$ among the Toxic multinodular goiter and Multinodular goiter respectively. Among the surgical procedures, total thyroidectomy was associated with the highest incidence (88.23\%) of complications, followed by Near total thyroidectomy (50\%), Subtotal thyroidectomy $(23.80 \%)$ and least by Hemithyroidectomy. The incidence rate of complications was high in patients with the malignant disease, with $69.23 \%$ as compared to $22.12 \%$ of the benign conditions reporting complications (Table 3 ).

Table-4: Histopathological diagnosis with the complication of each operative procedure.

\begin{tabular}{|c|c|c|c|c|c|}
\hline \multirow[b]{2}{*}{ Histological diagnosis } & \multirow[b]{2}{*}{$\begin{array}{l}\text { Total no } \\
\text { of } \\
\text { patients }\end{array}$} & \multicolumn{4}{|c|}{ Number of complications occurred in } \\
\hline & & Hemithyroidectomy & SBT & Near TT & $\begin{array}{c}\text { Total } \\
\text { Thyroidectom } \\
\mathbf{y}\end{array}$ \\
\hline Colloid and recurrent goiter & 3 & - & - & - & $3(100 \%)$ \\
\hline Solitary nodule of thyroid & 34 & $1(2.94 \%)$ & - & - & - \\
\hline Multinodular goiter & 45 & - & $8(17.7 \%)$ & - & $3(6.66 \%)$ \\
\hline Toxic multinodular goiter & 22 & - & $7(31.82 \%)$ & - & $1(4.54 \%)$ \\
\hline Thyroid carcinoma & 13 & - & - & $1(7.69 \%)$ & $8(61.54 \%)$ \\
\hline
\end{tabular}

All the 3 subjects with Colloid and recurrent goiter, underwent total thyroidectomy, and all of them developed complications. The only complication among people with a solitary nodule of thyroid happened with hemithyroidectomy. Among the 45 multinodular goiter patients, 8 (17.7\%) complications occurred with SBT and 3 (6.66\%) complications occurred with Total thyroidectomy. Among 22 cases of toxic multinodular goiter 7 (31.82\%) had complications with SBT and 1 (4.54\%) complication occurred with Total thyroidectomy. Among 13 cases of thyroid carcinoma1 (7.69\%), a complication occurred with near Total thyroidectomy, and 8 (61.54\%) complications occurred with Total thyroidectomy (Table 4).

\section{Discussion}

Worldwide, thyroid disease is very common. In India, approximately around 42 million people are affected by the thyroid disease. It is considered as the common most endocrine disorder [10]. The prevalence of thyroid disease and thyroid malignancy is high, with an increase in age [11]. Globally, one of the common most surgery performed is thyroidectomy. The incidence of complications following thyroidectomy is associated with the difficulty involved in the procedure performed [12]. Thyroid surgery is performed based on the type and severity of the thyroid disease. In this study, the incidence of thyroid disease and the comparison of complications associated with various thyroid surgeries were carried out.

In the present study, the number of females was more as compared to males. The present study resembles to the study performed in Pakistan by Hussain N et al [13] in which out of 662 cases, 570 were females and 92 were males. In a retrospective study conducted by Salami B et al [14] in a population of 175 patients majority of the patients were females with $86.3 \%$ followed by males with $13.8 \%$. Joseph E et al [15] performed a study in Kerala for a period of 6 years in a population of 801 in which 716 patients were females and 85 were males. In most of the published studies, the majority of the patients were females which indicates that the risk of developing the thyroid disease is high among the women as compared to men which can be due to various reasons. Among females, $40.19 \%$ of the patients was identified with multinodular goiter which is similar to the Kolur A et al [16] study published in 2014 in which majority of the patients with multinodular goiter was females with $92.24 \%$.

Depending upon the gender, age, ethnic and geographical pattern the prevalence and pattern of thyroid diseases can vary. In the current study majority of the patients was diagnosed with multinodular goiter with $38.46 \%$, followed by solitary nodule and colloid goiter with $29.06 \%$ and $2.56 \%$ which resembles the study result performed by Kolur A et al [16] in which $58.10 \%, 30.16 \%$ and $2.79 \%$ were identified with multinodular goiter, solitary nodule and colloid goiter. In the study performed by Haque GS et al [17] 48.5\% of patients was diagnosed with multinodular goiter. The most common thyroid disease in Hussain, $\mathrm{N}$ et al [13] study was multinodular goiter with $61.63 \%$ of patients. In a retrospective study conducted by Joseph E et al [15], in Kerala $71.5 \%$ of patients was identified with 


\section{Original Research Article}

multinodular goitre. The present study resembles Darwish A, et al [18], study which was conducted in a population of 110 patients in which $45.5 \%$ of patients was identified with nodular goiter followed by malignancy with $24 \%$. Out of 117 cases, $53.85 \%$ of cases underwent subtotal thyroidectomy followed by hemithyroidectomy, total thyroidectomy and near total thyroidectomy with $29.06 \%, 14.53 \%$ and $1.71 \%$ respectively.

In a study, Hussain A. et al [19] Performed in Pakistan the majority of the patients underwent subtotal thyroidectomy with $42.6 \%$ followed by hemithyroidectomy, total thyroidectomy and near total thyroidectomy with $36.5 \%, \quad 15.2 \%$ and $3.9 \%$ respectively which is similar to the current study.

The type of thyroid surgery performed varies in different studies based on the type of thyroid disease and study population. In various studies, the subtotal thyroidectomy is the surgery performed mainly for the thyroid disease.

Chen $\mathrm{KC}$ et al [20] Conducted a study on 314 cases in which $13.5 \%$ of patients undergoing bilateral total thyroidectomy. The majority of the patients underwent total thyroidectomy with $61.1 \%$ followed by subtotal thyroidectomy and near total thyroidectomy with 36\% and $2.4 \%$ respectively in a study performed by Vaiman $\mathrm{M}$ et al [21].

Majority of the patients identified with multinodular goiter in the present study underwent subtotal thyroidectomy and hemithyroidectomy. This was similar to the study conducted in Kerala by Kolur A et al [16] in a sample size of 179 participants in which patients presented with multinodular goiter was performed with subtotal thyroidectomy and hemithyroidectomy with $50.96 \%$ and $20.8 \%$ respectively. In the present study $84.16 \%$ of patients performed total thyroidectomy for thyroid malignancy.

Bhattacharyya $\mathrm{N}$ et al [4] presented a study in a population of 517 patients in which thyroid cancer was the most common indication for total thyroidectomy. The complications associated with thyroid surgery was high among total thyroidectomy and subtotal thyroidectomy.

The rate of complication varies between different thyroid surgeries. The complications which occur during and followed by the surgery can be reduced with the experience of the performing surgeon, monitoring and follow-up of the patients.
In the current study, the number of complications in total thyroidectomy and subtotal thyroidectomy performed for multinodular goiter was high with $6.66 \%$ and $17.7 \%$ respectively which is similar to the study done by Cifici $\mathrm{F}$ et al [22] in which $30.46 \%$ and $19.56 \%$ were the rate of complications followed by total thyroidectomy and subtotal thyroidectomy in multinodular goiter. The rate of complications varies based on the severity of disease and patient response.

In the present study, $11.11 \%$ of patients was identified with malignant disease. In a retrospective study conducted by Abdoulaye $\mathrm{O}$ et al [23] in a sample size of 53 patients for a period of 3 years $5.7 \%$ was reported with malignancy disease.

The rate of complications varies between patients with the malignant and benign disease based on the disease condition and management. The incidence rate of complications was high in patients with the malignant disease with $69.23 \%$ in the present study which is conflicting to the study result performed by Iddings D et al [9] in which majority of the patients had benign pathology with $68 \%$. In a study conducted for the population size of 83 , the complication rate for the malignant disease was $10 \%$ and $2 \%$ for benign diseases in Spear SA et al [7] study.

Limitations \& recommendations: The study sample size was very limited; hence, there is a higher probability of chance findings. There is a need to conduct further large scale studies on the subject, for the more in-depth understanding of the complication rate and the factors influencing them. Also, clinicians need to be aware of the common complications and their incidence among patients undergoing thyroid surgery for effective risk communication and prevention of complications.

\section{Conclusions}

Majority of the participants undergoing thyroid surgery in the current study were women, emphasizing a significantly higher risk of thyroid disease among women. Multinodular goiter (MNG) was the most common condition, followed by solitary nodule and toxic MNG for which thyroid surgery was performed.

In women, MNG was the most common condition, and in men, solitary nodule and toxic MNG were relatively common. Subtotal thyroidectomy and hemithyroidectomy were the common procedures performed on $\mathrm{mNG}$ and solitary nodule patients, respectively. More than one-fourth of the subjects developed 


\section{Original Research Article}

complications. The incidence rate of complications was high in patients with malignant disease, as compared to benign disease (MNG and toxic MNG). All three cases of colloid goiter developed complications in the study.

\section{What the study adds in the existing knowledge?}

The prevalence of thyroid diseases is increasing therefore there is a need of updating knowledge regarding this condition. The present study enhances the present knowledge regarding various thyroid diseases.

The complications involved in thyroid surgery is high thereby patients is at high risk. By understanding more about the condition surgeons can make patient selection more appropriate for surgery and rate of complications can be reduced. Physicians and other health care professionals can make patient more aware about their disease condition and its associated complications. It can reduce the post operative complications.

\section{Author's contribution}

Dr. Karpagavel Chandra Bose had conceptualized the study, prepared the study protocol, and conducted the data collection, analysis and manuscript writing. He has verified all the drafts and approved the final draft.

Dr. Vijaiaboobbathi Sathiah had provided key inputs on methodology during protocol preparation, supported data compilation and analysis. He has also edited all the drafts and approved the final draft of the manuscript.

Conflict of interest: None declared.

Funding: Nil, Permission from IRB: Yes

\section{References}

1. Padur AA, Kumar N, Guru A, Badagabettu SN, Shanthakumar SR, Virupakshamurthy MB, et al. Safety and Effectiveness of Total Thyroidectomy and Its Comparison with Subtotal Thyroidectomy and Other Thyroid Surgeries: A Systematic Review. J Thyroid Res. 2016;2016:7594615. doi: 10.1155/2016/7594615.

2. Rajgor D, Dash N, Gadekar J, Thorat P. Evaluation of total thyroidectomy for benign thyroid diseases. Indian J Basic Appl Med Res. 2016;6(1):5-11.

3. Ernandes Neto M, Tagliarini JV, López BE, Padovani $\mathrm{CR}$, Marques MdA, Castilho EC, et al. Fatores que influenciam nas complicações das tireoidectomias. Braz J Otorhinolaryngol. 2012; 78(3): 63-69. doi: 10.1590/ S 1808-86942012000300012.
4. Bhattacharyya N, Fried MP. Assessment of the morbidity and complications of total thyroidectomy. Arch Otolaryngol Head Neck Surg. 2002;128(4):389392. doi: 10.1001/archotol.128.4.389.

5. Vassiliou I, Tympa A, Arkadopoulos N, Nikolakopoulos F, Petropoulou T, Smyrniotis V. Total thyroidectomy as the single surgical option for benign and malignant thyroid disease: a surgical challenge. Arch Med Sci. 2013;9(1):74-78. doi: 10.5114/aoms. 2013.33065.

6. Gangappa RB, Kenchannavar MB, Chowdary PB, Patanki AM, Ishwar M. Total Thyroidectomy for Benign Thyroid Diseases: What is the Price to be Paid? J Clin Diagn Res.2016;10(6):PC04-PC07. doi: 10.7860/ JCDR/2016/18733.7991.

7. Spear SA, Theler J, Sorensen DM. Complications after the surgical treatment of malignant thyroid disease. Mil Med. 2008;173(4):399-402. doi: 10.7205/milmed. 173. 4.399 .

8. Zambudio AR, Rodriguez J, Riquelme J, Soria T, Canteras M, Parrilla P. Prospective study of postoperative complications after total thyroidectomy for multinodular goiters by surgeons with experience in endocrine surgery. Ann Surg. 2004;240(1):18-25. doi: 10.1097/01.sla.0000129357.58265.3c.

9. Iddings D, Saha S, Walsh E, Raiji M, Ghanem M, Rao V, et al. Comparison of complications of total thyroidectomy in malignant vs. benign thyroid tumors. J Clin Oncol. 2008;26(15):17012. doi: 10.1200/jco.2008. 26. 15_suppl.17012.

10. Unnikrishnan AG, Menon UV. Thyroid disorders in India: An epidemiological perspective. Indian J Endocrinol Metab. 2011;15(2):S78-81. doi: 10.4103/ 2230-8210.83329.

11. Sullivan MC, Roman SA, Sosa JA. Clinical and economic outcomes of thyroid surgery in elderly patients: a systematic review. J Thyroid Res.2012; 2012: 615846. doi: 10.1155/2012/615846.

12. Oommen A, Remin V. Predicting difficulty of thyroidectomy preoperatively. Int Surg J. 2017;4 (5):1605-1609. doi: 10.18203/2349-2902.isj 20171605.

13. Hussain N, Anwar M, Nadia N, Ali Z. Pattern of surgically treated thyroid disease in Karachi. Biomed. 2005;21:18-20. 


\section{Original Research Article}

14. Salami B, Odusan O, Ebili H, Akintola P. Spectrum and prevalence of thyroid diseases seen at a tertiary health facility in Sagamu, South-West Nigeria. Nigerian Postgraduat Med J. 2016;23(3):137-140. doi: 10.4103/ 1117-1936.190345.

15. Joseph E, Varghese A, T.M C, Matthai A, Poothiode U. A study on the histopathological pattern of thyroid lesions in a tertiary care hospital. Int J Res Med Sci. 2016;4(12):5252-5255. doi: 10.18203/23206012. ijrms20164189.

16. Kolur A, Anitha B, Letha P, Joshi T, Ahmed S, Naik H. et al. Pattern of thyroid disorder in thyroidectomy specimen. Int J Med Sci Public Health. 2014;3(12): 1446-1449. doi: 10.5455/ijmsph.2014. 110920141.

17. Haque GS, Farid N, Islam SS. Incidence of Complications of Thyroid Surgery. Med Today (Karachi). 2016;28(2):62-65.

18. Darwish AH, Al Sindi KA, El Kafsi J, BAcantab M. Pattern of thyroid diseases-A histopathological study. Bahrain Med Bull. 2006;28(4):1-6.
19. Hussain A, Muhammad T, Arif S, Din Iu, Muhammad G. Complications of different types of thyroid surgery. J Med Sci. 2016;24(3):163-166.

20. Chen KC, Iqbal U, Nguyen PA, Hsu CH, Huang $\mathrm{CL}$, Hsu YE, et al. The impact of different surgical procedures on hypoparathyroidism after thyroidectomy: A population-based study. Medicine (Baltimore). 2017; 96 (43):e8245. doi: 10.1097/MD.0000000000008245.

21. Vaiman M, Nagibin A, Hagag P, Buyankin A, Olevson J, Shlamkovich N. Subtotal and near total versus total thyroidectomy for the management of multinodular goiter. World J Surg. 2008;32(7):15461551. doi: 10.1007/s00268-008-9541-9.

22. Ciftci F, Sakalli E, Abdurrahman I. Total versus bilateral subtotal thyroidectomy for benign multinodular goiter. Int J Clin Exp Med. 2015;8 (3): 45964600 .

23. Ouattara MA, Togo S, Sankaré I, Singaré K, Koumaré S, Maiga I, et al. Total Thyroidectomy in Multinodular Goiter: An African Experience. Surg Sci. 2015;06(12):527-531. doi: 10.4236/ss.2015.612075.

\section{How to cite this article?}

Vijaiaboobbathi S, Karpagavel C. Profile and complication rate of thyroid surgeries performed in a tertiary care teaching hospital, a prospective observational study. Surgical Update: Int J surg Orthopedics.2019;5(4):281-287.doi:10.17511/ ijoso.2019.i04.08 